\title{
Redescription of Parapercis moki Ho and Johnson, 2013 (family Pinguipedidae), with its first fresh coloration information
}

\author{
HSUAN-CHING HO ${ }^{1,2,3}$, CHI-NGAI TANG ${ }^{4} \&$ HSIANG-CHIEH CHUANG ${ }^{5 *}$ \\ ${ }^{1}$ National Museum of Marine Biology \& Aquarium, Pingtung, Taiwan. ㄴ) https://orcid.org/0000-0003-1154-601X \\ ${ }^{2}$ Institute of Marine Biology, National Dong Hwa University, Pingtung, Taiwan \\ ${ }^{3}$ Australian Museum, Sydney, Australia (Research Associate) \\ ${ }^{4}$ Department of Oceanography, National Taiwan University, Taipei, Taiwan \\ (1) https://orcid.org/0000-0002-8140-8459 \\ ${ }^{5}$ Department and Graduate Institute of Aquaculture, National Kaohsiung University of Science and Technology, Kaohsiung, Taiwan \\ (1) https://orcid.org/0000-0001-7713-0979 \\ "Corresponding author. झ" hcchuang@nkust.edu.tw
}

\begin{abstract}
Two specimens of Parapercis moki Ho \& Johnson were collected recently and detailed descriptions of their morphology and fresh coloration are provided. Its diagnosis is now revised as: band across head, six transverse bands on body and blade-like bar below eye; numerous small pores connected by canals forming about 9-10 vertical rows on cheek, opercle, and subopercle; scales on nape extending anteriorly to level of posterior margin of eyes; large spine on posteroventral corner of subopercle; very narrow interorbital space (1.7-2.0\% SL); 4 dorsal-fin spines, each spine progressively longer, last spine entirely connected by membrane to first dorsal-fin ray; four pairs of canine teeth anteriorly in lower jaw; and palatine teeth present, in two rows, and vomerine teeth stout, in two rows.
\end{abstract}

Key words: Teleostei, Actinopteri, taxonomy, ichthyology, Taiwan

\section{Introduction}

Ho \& Johnson (2013) described a new species, Parapercis moki, based on a single, long-term preserved specimen with faded pigmentation, collected from southwestern Taiwan. Recently, two fresh specimens collected from Ketzu-liao, southwestern Taiwan, not far from the type locality, were identified as $P$. moki by the authors. The fresh coloration of $P$. moki was unknown previously due to the lack of fresh-caught specimens. Based on examination of the holotype and the two additional recently collected specimens, we are able to provide detailed information on the fresh coloration, morphological variation, and revised diagnostic characters of this rare fish.

\section{Materials and methods}

Specimens examined in this study are housed at National Museum of Marine Biology \& Aquarium, Pingtung, Taiwan (NMMB-P). Methods for taking measurements and counts generally followed Randall et al. (2008), and all measurements were made point to point. Vertebral counts were made by a digital radiography machine at National Museum of Marine Biology \& Aquarium. The holotype was re-examined and measured; data are provided in Table 1.

\section{Results}

\section{Family Pinguipedidae}




\section{Parapercis moki Ho \& Johnson, 2013}

Mok's sandperch

Figs. 1-2; Table 1

Parapercis moki Ho \& Johnson, 2013: 279, fig. 2A-B (type locality: Chong-Chou, Kaohsiung, southwestern Taiwan, northern South China Sea). Ho, 2014a: 77 (in key). Ho, 2014b: 589 (mentioned, comparison).

Specimens examined. Holotype: NMMB-P00892, $105.5 \mathrm{~mm}$ (104.4 mm SL in original description), Chong-chou, Kaohsiung, southwestern Taiwan, northern tip of South China Sea, 29 Nov. 1984. Non-types: NMMB-P35214, 58.6 mm SL, Ke-tzu-liao, Kaohsiung, southwestern Taiwan, 24 Jan. 2021, coll. C.-N. Tang; NMMB-P35695, 92.3 mm SL, Ke-tzu-liao, Kaohsiung, southwestern Taiwan, 20 Aug. 2021, coll. Y.-C. Chen.

Diagnosis. A species of Parapercis with band across head, six transverse bands on body and blade-like bar below eye; numerous small pores connected by canals forming about 9-10 vertical rows on cheek, opercle, and subopercle; scales on nape extending anteriorly to level of posterior margin of eyes; large spine on posteroventral corner of subopercle; very narrow interorbital space $(1.7-2.0 \% \mathrm{SL}) ; 4$ dorsal-fin spines, each spine progressively longer, last spine entirely connected by membrane to first dorsal-fin ray; four pairs of canine teeth anteriorly in lower jaw; palatine teeth present, in two rows; and vomerine teeth stout, in two rows (revised from the original description).

Description. Morphometric data based on the holotype and two additional specimens are provided in Table 1. The following data are provided for the holotype, followed by values of NMMB-P35695 (92.3 mm SL) and NMMB-P35214 (58.6 mm SL), respectively, in parentheses, when different, unless otherwise indicated.

Dorsal-fin rays IV, 23; anal-fin rays I, 19; all dorsal and anal soft rays branched, last to base; pectoral-fin rays 18 (left side)/19 (right side) $(19 / 19,19 / 19)$, branched except uppermost; pelvic-fin rays I, 5; principal caudal-fin rays 9 (upper) +8 (lower) $=17$; upper procurrent caudal-fin rays $9(9,8)$; lower procurrent caudal-fin rays 7 ; pored lateral-line scales 56 , not including $2(3,2)$ pored scales on base of caudal fin; scales above first lateral-line scale to origin of dorsal fin 4; scales above highest part of lateral line to base of dorsal fin 3; scales below lateral line posteroventrally to origin of anal fin about 17 (16, damaged); median predorsal scales 12 (counted to level of posterior margin of eye); circumpeduncular scales $26(25,25)$; gill rakers of outer first gill arch $5+9(9,10)=14(14,15)$; pseudobranchial filaments $16(14,13)$; branchiostegal rays 6 ; vertebrae $10+23(22,22)=33(32,32)$.

Body relatively slender, its depth $6.0(6.5,7.1)$ times in SL, $1.7(1.7,2.0)$ in HL; body subcylindrical anteriorly, width $5.6(5.7,5.8)$ in SL, $1.6(1.5,1.6)$ in $\mathrm{HL}$, strongly compressed posteriorly; head relatively short, somewhat depressed, its length $3.6(3.7,3.6)$ in SL; ventral part of head, chest, and abdomen slightly convex (flat in both nontypes); snout relatively short, its length $3.4(3.7,4.5)$ in HL; eye relatively large, orbit diameter $3.1(3.1,2.6)$ in HL; interorbital space very narrow and flat, least fleshy width $1.7(2.0,1.8) \% \mathrm{SL}$ or $6.1(7.6,6.5) \% \mathrm{HL}$; caudalpeduncle depth $3.3(3.0,3.3)$ in HL; caudal-peduncle length 3.0 in HL.

Mouth large, maxilla not quite reaching vertical through center of eye, upper jaw relatively short, its length $2.4(2.4,2.7)$ in $\mathrm{HL}$; mouth slightly oblique, forming an angle of about $20^{\circ}$ to horizontal axis of body, lower jaw projecting; front of lower jaw with 4 pairs of recurved canine teeth, middle one on each side twice as large as rest; side of upper jaw with row of about $24(24,20)$ slender conical teeth that curve medially and posteriorly, anterior 8 increasingly larger and more strongly recurved; remaining teeth in outer row on side of jaw decreasing in length; broad band of villiform teeth medial to canines in about 7 rows at front of upper jaw, gradually narrowing posteriorly to narrow band in about 3 irregular rows; front of lower jaw with 4 pairs of incurved canine teeth, increasing in length laterally, $4^{\text {th }}$ twice as large as $1^{\text {st }}$ and strongly curving laterally as well as posteriorly; band of about 5 rows of villiform teeth medial to canines at front of lower jaw, medial row continuing laterally in jaw posterior to last canine as row of 7 increasingly larger and more strongly recurved teeth, followed by single row of small teeth, with an additional inner row of 3 teeth at posterior part, to end of jaw; vomer with triangular patch of stout conical teeth, $7(7,6)$ on anterior margin largest, lateral and posterior ones progressively smaller; palatine with two rows of stout teeth, those on outer row larger than those on inner row; lips smooth, their inner surface with large fleshy papillae that interdigitate with anterior teeth; tongue broadly rounded, reaching forward to posterior vomerine teeth.

Gill membranes free from isthmus, with broad transverse free fold. Gill rakers short and spinous, longest about half length of longest gill filament. Nostrils small, anterior nostril anterior to center of eye (viewed laterally), little less than half way to groove at margin of upper lip, with high anterior rim and pointed posterior flap that reaches nearly anterior margin of posterior nostril when laid back; posterior nostril dorsoposterior to anterior nostril, its aperture ovate, with slight anterior rim. 
TABLE 1. Morphometric and meristic data of Parapercis moki. * data from original description.

\begin{tabular}{|c|c|c|c|c|c|c|c|}
\hline \multirow{3}{*}{$\begin{array}{l}\text { Standard length (mm) } \\
\text { Morphometrics }\end{array}$} & \multicolumn{3}{|c|}{ NMMB-P00892 } & \multirow{2}{*}{\multicolumn{2}{|c|}{$\begin{array}{c}\text { NMMB-P35695 } \\
92.3\end{array}$}} & \multirow{2}{*}{\multicolumn{2}{|c|}{$\frac{\text { NMMB-P35214 }}{58.6}$}} \\
\hline & \multirow{2}{*}{$\frac{104.4^{*}}{\% \mathrm{SL}}$} & \multicolumn{2}{|c|}{105.5} & & & & \\
\hline & & $\% \mathrm{SL}$ & $\% \mathrm{HL}$ & $\% \mathrm{SL}$ & $\% \mathrm{HL}$ & $\% \mathrm{SL}$ & $\% \mathrm{HL}$ \\
\hline Body depth & 17.7 & 16.6 & 59.5 & 15.5 & 57.4 & 14.2 & 50.3 \\
\hline Body width & 18.8 & 17.8 & 63.9 & 17.5 & 64.9 & 17.2 & 61.2 \\
\hline Head length & 28.4 & 27.9 & 100.0 & 27.0 & 100.0 & 28.2 & 100.0 \\
\hline Snout length & 6.8 & 8.2 & 29.6 & 7.3 & 26.9 & 6.3 & 22.4 \\
\hline Orbital diameter & 9.2 & 8.9 & 31.9 & 8.7 & 32.1 & 10.8 & 38.2 \\
\hline Interorbital width & 1.6 & 1.7 & 6.1 & 2.0 & 7.6 & 1.8 & 6.5 \\
\hline Post-orbital width & - & 12.1 & 43.5 & 12.6 & 46.6 & 12.0 & 42.8 \\
\hline Upper-jaw length & 11.6 & 11.8 & 42.2 & 11.2 & 41.4 & 10.6 & 37.6 \\
\hline Predorsal length & 30.7 & 29.8 & 106.8 & 28.6 & 106.0 & 29.7 & 105.5 \\
\hline Preanal length & 48.5 & 47.4 & 170.1 & 44.4 & 164.7 & 48.1 & 170.9 \\
\hline Prepelvic length & 27.3 & 25.8 & 92.5 & 24.3 & 90.0 & 25.6 & 90.9 \\
\hline Caudal-peduncle depth & 8.1 & 8.5 & 30.6 & 9.0 & 33.3 & 8.6 & 30.7 \\
\hline Caudal-peduncle length & 7.7 & 8.0 & 28.6 & 8.0 & 29.7 & 7.7 & 27.3 \\
\hline Dorsal-fin base length & 63.9 & 64.2 & 230.3 & 64.5 & 239.0 & 62.3 & 221.2 \\
\hline $1^{\text {st }}$ dorsal-fin spine & 5.3 & 5.5 & 19.7 & 3.7 & 13.7 & 3.8 & 13.3 \\
\hline $2^{\text {nd }}$ dorsal-fin spine & 6.8 & 6.8 & 24.3 & 5.6 & 20.9 & 5.6 & 20.0 \\
\hline $3^{\text {rd }}$ dorsal-fin spine & 7.5 & 7.9 & 28.2 & 6.6 & 24.5 & 6.7 & 23.6 \\
\hline $4^{\text {th }}$ dorsal-fin spine & 8.6 & 8.5 & 30.6 & 7.4 & 27.3 & 7.3 & 26.1 \\
\hline Longest dorsal-fin ray & 14.0 & 13.2 & 47.3 & 15.2 & 56.2 & 13.7 & 48.5 \\
\hline Anal-fin base length & 45.0 & 43.6 & 156.5 & 46.5 & 172.3 & 44.0 & 156.4 \\
\hline Anal-fin spine & 4.0 & 4.4 & 15.6 & 3.4 & 12.4 & 6.5 & 23.0 \\
\hline Longest anal-fin ray & 11.7 & 11.3 & 40.5 & 11.3 & 41.8 & 11.9 & 42.4 \\
\hline Caudal-fin length & 17.7 & 17.7 & 63.6 & 18.5 & 68.7 & 20.1 & 71.5 \\
\hline Pectoral-fin length & 21.6 & 20.0 & 71.8 & 21.1 & 78.3 & 21.7 & 77.0 \\
\hline Pelvic-fin spine length & - & 8.3 & 29.8 & 7.8 & 28.9 & 8.4 & 29.7 \\
\hline Pelvic-fin length & 19.4 & 19.5 & 70.1 & 19.2 & 71.1 & 19.8 & 70.3 \\
\hline \multicolumn{8}{|l|}{ Meristics } \\
\hline Dorsal-fin elements & \multicolumn{3}{|c|}{ IV, 23} & \multicolumn{2}{|c|}{ IV, 23} & \multicolumn{2}{|c|}{ IV, 23} \\
\hline Anal-fin elements & \multicolumn{3}{|c|}{$\mathrm{I}, 19$} & \multicolumn{2}{|c|}{$\mathrm{I}, 19$} & \multicolumn{2}{|c|}{$\mathrm{I}, 19$} \\
\hline Pectoral-fin rays & \multicolumn{3}{|c|}{$18 ; 19$} & \multicolumn{2}{|c|}{19} & \multicolumn{2}{|c|}{19} \\
\hline Caudal-fin rays & \multicolumn{3}{|c|}{$9+9+8+7$} & \multicolumn{2}{|c|}{$9+9+8+7$} & \multicolumn{2}{|c|}{$8+9+8+7$} \\
\hline Vertebrae & \multicolumn{3}{|c|}{$10+23$} & \multicolumn{2}{|c|}{$10+22$} & \multicolumn{2}{|c|}{$10+22$} \\
\hline Pored lateral-line scales & \multicolumn{3}{|c|}{$56+2$} & \multicolumn{2}{|c|}{$56+3$} & \multicolumn{2}{|c|}{$56+2$} \\
\hline Predorsal scales & & 12 & & & & & \\
\hline Transverse scale rows & & $4 / 17$ & & & & & \\
\hline Circumpeduncular scales & & 26 & & & & & \\
\hline Gill rakers & & $5+9$ & & & & & \\
\hline Pseudobranchial filaments & & 16 & & & & & \\
\hline
\end{tabular}

Pores of cephalic sensory system with row of 3 large pores above maxilla; 3 pores near nostrils, one above, one between, and one below; row of 3 pores on either side anteriorly in interorbital space; irregular series of small pores medially on posterior half of interorbital space; numerous small pores with subcutaneous canals posteriorly on occiput, pores divided into several irregular double series, from anterior end of lateral line on body, continuing to ventral margin of eye, opercle, and subopercle; cheek with 8 or $9(8,9)$ irregular double series of pores connected by 
canals; series of $10(12,11)$ small pores along margin of preopercle; series of 4 large pores on mandible; two medial pores at front of chin.

Opercle with single sharp spine level with ventral margin of pupil (when viewed laterally); subopercle with single sharp spine at posteroventral corner; preopercle broadly rounded, its free edge smooth except for slight indentations at each pore site, extending from level of ventral edge of orbit downward and forward to slightly in front of vertical at posterior edge of orbit.

Scales finely ctenoid on body, becoming cycloid anterior to line from base of third dorsal spine to anterior end of lateral line, extending forward to vertical from posterior margin of eye; scales on base of pectoral fin ctenoid, those on area anterior to pelvic-fin base, opercle, and subopercle cycloid; cheek scales cycloid, in about 9 irregular horizontal rows, relatively large and nonimbricate, extending anteriorly to vertical from anterior $1 / 3$ of eye; progressively smaller scales extending out on basal portion of caudal fin for at least $2 / 3$ length of fin; base of pectoral fin with up to 4 rows of small cycloid scales; lateral line broadly arched over pectoral fin, then gradually slanting to straight midlateral portion on about posterior fourth of lateral body.

Origin of dorsal fin over third lateral-line scale, predorsal length $3.4(3.5,3.4)$ in SL, equal to head length; 4 dorsal-fin spines, all relatively slender, progressively longer posteriorly; $1^{\text {st }}$ dorsal-fin spine $5.1(7.3,7.5)$ in HL; $2^{\text {nd }}$ dorsal-fin spine $4.1(4.8,5.0)$ in HL; $3^{\text {rd }}$ dorsal-fin spine $3.5(4.1,4.2)$ in HL; $4^{\text {th }}$ dorsal-fin spine longest 3.3 (3.7, 3.8 ) in HL, full length of spine attached to $1^{\text {st }}$ soft ray by membrane (membrane damaged in holotype); penultimate dorsal-fin soft ray longest, $2.1(1.8,2.1)$ in HL; origin of anal fin below base of $4^{\text {th }}$ dorsal-fin soft ray, preanal length $2.1(2.3,2.1)$ in SL; anal-fin spine $6.4(8.0,4.3)$ in HL; penultimate anal-fin soft ray longest, $2.5(2.4,2.4)$ in HL; caudal fin rounded, without prolonged upper lobe; caudal-fin length 5.6 $(5.4,5.1)$ in SL, $1.6(1.5,1.4)$ in HL; pectoral fins broadly rounded when spread, $10^{\text {th }}$ ray longest, $5.0(4.7 .4 .6)$ in SL, $1.4(1.3,1.3)$ in HL; origin of pelvic fins anterior to pectoral-fin origin, below base of exposed part of opercular spine, prepelvic length $3.9(4.1,3.9)$ in SL, 1.1 in HL; pelvic-fin spine slender, $3.4(3.5,3.4)$ in HL; pelvic fins extending to genital papilla, but not reaching origin of anal fin; $4^{\text {th }}$ soft pelvic-fin ray longest, $5.1(5.2,5.1)$ in SL, 1.4 in HL.

Color when fresh. Based on 2 nontypes. Body brownish red dorsally and gradually paler ventrally in general (Fig. 1A, B, D); blackish yellow stripes on head and body: blade-like bar on cheek immediately below eye; vertical band across nape, its lower end extending to lower margin of subopercle; 6 slightly oblique bands on flank of body, $1^{\text {st }}$ band at front of dorsal fin and extending to posterior portion of pectoral-fin base (covered by fin when adpressed), $2^{\text {nd }}$ to $6^{\text {th }}$ bands originating from soft dorsal-fin base with their lower ends extending to abdomen $\left(2^{\text {nd }}\right)$ or anal-fin base $\left(3^{\text {rd }}-6^{\text {th }}\right)$. Upper portion of eye blackish with thick yellow margin; pink stripe above and below pupil; yellow coloration anterior and posterior to pupil (Fig. 2A, B). Membranes across isthmus light orange red (Fig. 2C). Spinous dorsal fin red with white base, small white patches present on upper portion of fin membranes (NMMBP35695 only); soft dorsal fin and anal fin light yellow with indistinct pale marks; pectoral fin light yellow with pink or orange patch on fin-ray bases; pelvic fin red (NMMB-P35695) or pale with reddish color (NMMB-P35214). An eye spot, black circled with white pigmentation, at upper corner of caudal-fin base, slightly larger than pupil; caudal fin light yellow, with 5 narrow, bluish oblique bands across entire fin.

Color in alcohol (Fig. 1C). Uniformly light brown with 6 slightly oblique narrow bars laterally on upper body, each bar of approximately equal width, extending from base of dorsal fin to slightly below midbody; $1^{\text {st }}$ bar at front of spinous dorsal fin and posterior base of pectoral fin; $2^{\text {nd }}$ at base of $2^{\text {nd }}-3^{\text {rd }}$ dorsal-fin rays; $3^{\text {rd }}$ at $6^{\text {th }}-8^{\text {th }}$ rays; fourth at $11^{\text {th }}-12^{\text {th }}$ rays; $5^{\text {th }}$ at $16^{\text {th }}-17^{\text {th }}$ rays; and $6^{\text {th }}$ at $21^{\text {st }}-22^{\text {nd }}$ rays. Gray blade-like bar immediately below eye in 2 freshcaught specimens. Black spot at upper corner of caudal fin base, from last procurrent to $7^{\text {th }}$ ray of upper lobe, slightly larger than pupil. All fins pale, caudal fin pale with 5 narrow oblique bands across fin.

Distribution. Known from southwestern Taiwan off Chong-chou and Ke-tzu-liao, Kaohsiung. Depth assumed not more than $100 \mathrm{~m}$. It likely inhabits shallow waters in the southeastern Taiwan Strait.

Remarks. The first specimen (holotype) was collected in 1984 and no specimens were available to describe coloration in life at the time of the original description (Ho \& Johnson, 2013). Two additional specimens were collected more recently and detailed information regarding their live coloration is added herein.

Of the Parepercis species with a banded body (see key in Ho \& Johnson, 2013), Parapercis moki is most similar to Parapercis sexlorata Johnson, 2006 in having 4 dorsal-fin spines and 6 bands on the flanks of the body. The following comparison includes the fresh coloration which was not available previously. 


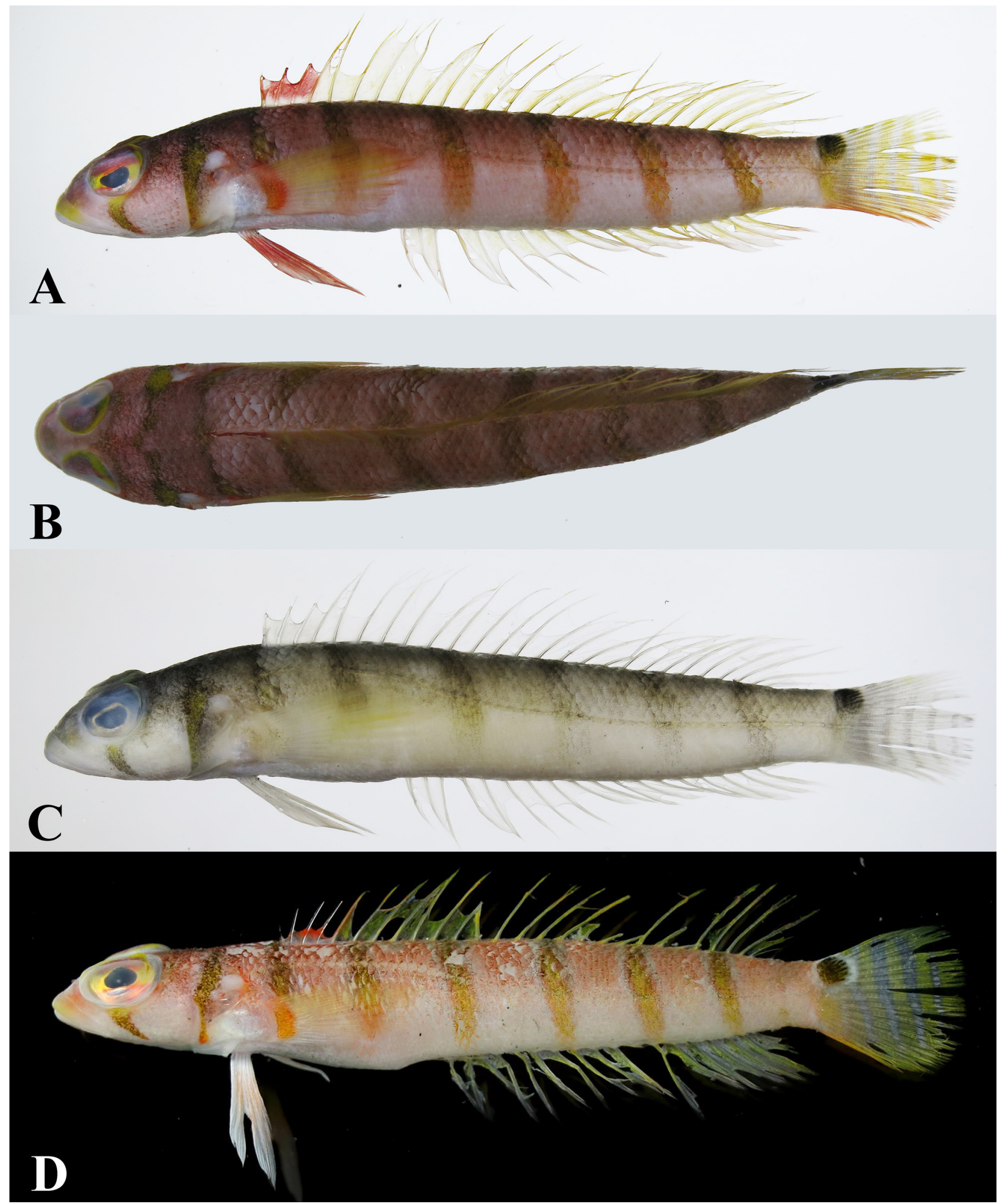

FIGURE 1. Parapercis moki Ho \& Johnson, 2013. A-C. NMMB-P35695, $92.3 \mathrm{~mm} \mathrm{SL}, 1^{\text {st }}$ dorsal-fin spine overlapped with $2^{\text {nd }}$ spine. D. NMMB-P35214, 58.6 mm SL. A. Lateral view. B. Dorsal view. C. Preserved condition, lateral view. D. Fresh, lateral view. 

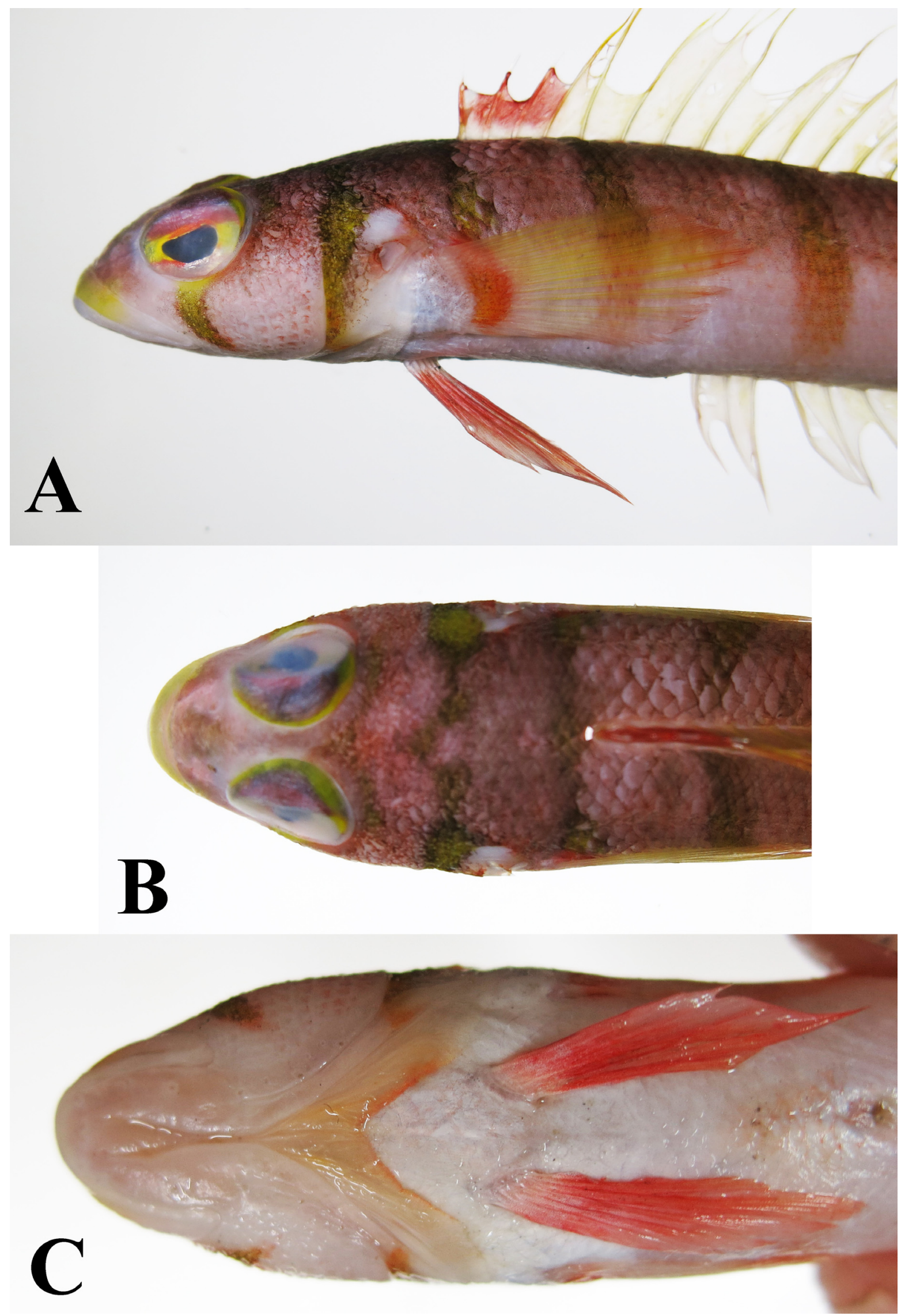

FIGURE 2. Close-ups of head and anterior trunk of Parapercies moki, NMMB-P35695, $92.3 \mathrm{~mm}$ SL. A. Lateral view of left side, $1^{\text {st }}$ dorsal-fin spine overlapped with $2^{\text {nd }}$ spine. B. Dorsal view. C. Ventral view. 
Parapercis moki differs from P. sexlorata in having 4 pairs of conical teeth anteriorly in the outer row of the lower jaw (vs. 3 pairs); a strong spine on the posteroventral corner of the subopercle (vs. some feeble spinules); and a relatively slender body (vs. a relatively stout body). The fresh colorations of both species are also quite distinct. Parapercis moki has a clear blade-like bar right below the eye (vs. absent in P. sexlorata); a clear band across nape, extending to lower portion of subopercle (vs. no regular band); spinous dorsal fin red with pale base (vs. spinous dorsal fin pale with black patches); bands on body not solid black (vs. bands solid black with lower portions yellow); pectoral-fin base with a red or orange patch (vs. pectoral-fin base yellow with black dots); regions between bands on dorsum not especially blackish (vs. clearly blackish); pelvic fin without black (vs. pelvic fin with black patch); and eye spot on caudal-fin base slightly larger than pupil (vs. spot smaller than pupil).

Although only three specimens are available for this study, some variation or growth changes were observed (see Table 1 for detailed comparison). The body depth and body width increased with body length. The original snout length $(6.8 \% \mathrm{SL})$, measured from the horizontal distance, is now modified to $8.2 \% \mathrm{SL}$ (measured from point to point). The snout length also shows a positive growth trend. The eye diameter is relatively large $(10.8 \% \mathrm{SL})$ in the 58.6-mm specimen, whereas the other two specimens have smaller eyes. The ratio of eye diameter/snout length is 1.7 in the $58.6-\mathrm{mm}$ specimen, whereas that of the $92.3-\mathrm{mm}$ and $105.5-\mathrm{mm}$ (holotype) specimens are 1.1 and 1.4, respectively. The upper-jaw length is relatively short in the 58.6-mm specimen $(10.6 \% \mathrm{SL})$, whereas the jaw length is slightly longer in the other two specimens $(11.2 \%$ and $11.8 \% \mathrm{SL}$, respectively). The $58.6-\mathrm{mm}$ specimen has a relatively long preanal length $(48.1 \% \mathrm{SL})$, whereas the $92.3-\mathrm{mm}$ specimen has a shorter preanal length $(44.4 \% \mathrm{SL})$. The length of the dorsal-fin base is relatively short in the $58.6-\mathrm{mm}$ specimen $(62.3 \% \mathrm{SL})$, whereas the other two specimens have longer fin bases $(64.5 \%$ and $64.2 \% \mathrm{SL}$, respectively).

All 4 dorsal-fin spines are relatively long in the holotype $\left(1^{\text {st }}\right.$ to $4^{\text {th }}$ spines $5.5 \%, 6.8 \%, 7.9 \%, 8.5 \% \mathrm{SL}$, respectively), whereas the dorsal-fin spines are shorter in the other two specimens $(3.7 \%, 5.6 \%, 6.6 \%, 7.4 \% \mathrm{SL}$, respectively, in $92.3-\mathrm{mm}$ specimen; $3.8 \%, 5.6 \%, 6.7 \%, 7.3 \% \mathrm{SL}$, respectively, in the $58.6-\mathrm{mm}$ specimen). The anal-fin spine is relatively long in the $58.6-\mathrm{mm}$ specimen $(6.5 \% \mathrm{SL})$ and relatively short in the $92.3-\mathrm{mm}$ specimen $(3.4 \%$ $\mathrm{SL})$. The caudal fin is relatively long in the $58.6-\mathrm{mm}$ specimen $(20.1 \% \mathrm{SL})$ and moderately long $(18.5 \% \mathrm{SL})$ in the 92.3-mm specimen and $17.7 \%$ SL in the holotype. More specimens may give a better understanding of the individual variations or growth changes.

\section{Acknowledgements}

We thank Mr. Y.-C. Chen for collecting one new specimen and making it available for this study. This study was supported by the National Museum of Marine Biology \& Aquarium and National Kaohsiung University of Science and Technology, Taiwan.

\section{References}

Ho, H.-C. (2014a) New record of whitespot sandperch Parapercis alboguttata (Günther, 1872) from Taiwan, with a key to sandperches of Taiwan. Platax, 11, 71-81. https://doi.org/10.29926/PLATAX.201412_2014.0006

Ho, H.-C. (2014b) Redescription of Parapercis okamurai Kamohara, 1960 (Perciformes: Pinguipedidae), based on specimens newly collected from Taiwan and Japan. Zootaxa, 3857 (4), 581-590. https://doi.org/10.11646/zootaxa.3857.4.7

Ho, H.-C. \& Johnson, J.W. (2013) Redescription of Parapercis macrophthalma (Pietschmann, 1911) and description of a new species of Parapercis (Pisces: Pinguipedidae) from Taiwan. Zootaxa, 3620 (2), 273-282. https://doi.org/10.11646/zootaxa.3620.2.5

Johnson, J.W. (2006) Two new species of Parapercis (Perciformes: Pinguipedidae) from north-eastern Australia, and rediscovery of Parapercis colemani Randall \& Francis, 1993. Memoirs of Museum Victoria, 63 (1), 47-56. https://doi.org/10.24199/j.mmv.2006.63.7

Randall, J.E., Senou, H. \& Yoshino, T. (2008) Three new pinguipedid fishes of the genus Parapercis from Japan. Bulletin of the National Museum of Nature and Science, Series A (Zoology), Supplement 2, 69-84. 